\title{
Hormonal and metabolic substrate status in response to exercise in men of different phenotype
}

\author{
J Chycki', A Zajac ${ }^{1}$, M Michalczyk ${ }^{2}$, A Maszczyk ${ }^{3}$ and J Langfort ${ }^{2}$ \\ 'Department of Sports Training, The Jerzy Kukuczka Academy of Physical Education in Katowice, Katowice, Poland \\ 2Department of Sports Nutrition, The Jerzy Kukuczka Academy of Physical Education in Katowice, Katowice, Poland \\ ${ }^{3}$ Department of Methodology and Statistics, The Jerzy Kukuczka Academy of Physical Education in Katowice, Katowice, Poland
}

Correspondence should be addressed to J Chycki: j.chycki@awf.katowice.pl

\begin{abstract}
Objectives: The present study verified the effect of moderate-to-high-intensity aerobic exercise on the endocrine response profile and adipose tissue in young healthy men with different phenotype characteristics.

Design: Eighteen men were divided into three experimental groups with defined body components and specific physical fitness: Endurance phenotype - EP ( $n=6$; low body mass; low fat content; aerobic endurance trained), Athletic phenotype - AP ( $n=6$; high body mass; low fat content, resistance trained), Obesity phenotype - OP ( $n=6$; high body mass; high fat content, untrained).

Methods: The participants performed an progressive exercise protocol on a treadmill $\left(30 \% \mathrm{VO}_{2 \max }, 50 \% \mathrm{VO}_{2 \max }, 70 \% \mathrm{VO}_{2 \max }\right.$ ), separated by $45 \mathrm{~s}$ of passive rest for blood collection.

Results: Plasma glucose oxidation increased in relation to exercise intensity, but to a greater extent in the AP group. The free fatty acids' plasma level decreased with a rise in exercise intensity, but with different kinetics in particular phenotypes. Plasma growth hormone increased after the cessation of exercise and was significantly higher in all groups 45 min into recovery compared to resting values. Plasma insulin decreased during exercise in all groups, but in the OP, the decrease was blunted.

Conclusions: The results indicate that the rate of lipolysis, hormonal and metabolic response to aerobic exercise depends on the individuals' phenotype. Thus, exercise type, duration and intensity have to be strictly individualized in relation to phenotype in order to reach optimal metabolic benefits.
\end{abstract}

\author{
Key Words \\ - free fatty acid metabolism \\ - endocrine response \\ - lipolytic hormones \\ - phenotype \\ - exercise metabolism
}

Endocrine Connections (2019) 8, 814-821

\section{Introduction}

Somatotypes, which to some extent express genetic determinism, are significantly associated with the level of physical fitness $(1,2)$, and as a consequence with the content of adipose tissue (1). Adipocytes are highly metabolically active cells releasing adipokines and adipocytokines which affect the processes in neighboring and distant cells by autocrine, paracrine and endocrine fashion (3). The rate of release of the above mentioned adipocyte-derived factors can be modified by environmental changes, among which physical activity and dietary habits play a vital role.

Adipose tissue (AT) does not display homogenous properties, and its physiological role depends on the location in the body $(4,5)$. Considering body metabolism, the white adipose tissue (WAT) also referred to as subcutaneous or visceral fat (intraabdominal: mesenteric, 
perirenal and epididymal depots) serves as a primary energy store, and lipolysis in WAT is a crucial process for whole-body energy homeostasis. Physical exercise is recognized as a strong environmental stimulus of lipolysis in WAT, being a significant preventive factor against the so-called non-communicable diseases $(2,5)$. Most exercise protocols designed to induce AT loss have focused on regular steady-state aerobic exercise (6). In response to moderate-intensity aerobic exercise ( $30-60 \%$ $\left.\mathrm{VO}_{2 \max }\right)$ whole-body lipolysis is increased two- to threefold compared with resting values $(6,7,8)$. When exercise intensity increases (above $\sim 50 \% \mathrm{VO}_{2 \max }$ for the general population), lipid oxidation starts to decrease and drops dramatically once the intensity exceeds $80 \%$ of $\mathrm{VO}_{2 \max }(6$, 9 ). On the other hand, some authors suggest that higher exercise intensity $\left(>70 \% \mathrm{VO}_{2 \max }\right.$, HIIE) has the potential to be an economical and effective form of reducing body fat (10).

Exercise reveals the influence on the rate of AT lipolysis via stimulation of release of both lipolytic and antilipolytic hormones in an exercise intensitydependent manner (9). Endocrine exercise response depends on body mass, fat mass content and subjects' training status (11). It implies a possible role of phenotype as a factor modifying AT lipolysis response to hormonal action. In line with such an assumption are studies investigating fat oxidation during exercise in obese and lean subjects albeit mechanisms responsible for the above mentioned response are not fully recognized and provide conflicting data (12). For example, the plasma concentrations of non-esterified fatty acids (NEFAs) are not significantly different in high-intensity compared to low-intensity aerobic exercise (13). Moreover, postexercise circulating NEFA and fat oxidation remain in stimulation for several hours (13), which indicates the essential contribution of AT in resting post-exercise metabolism. Thus, the ability to alternate between storage and breakdown of AT is crucial for a healthy substrate metabolism in humans (14).

Most of the above mentioned study outcomes have been obtained during steady-state endurance exercises. However, there remains a paucity of evidence on how continuous running with low, moderate, or high intensity during a single continuous bout of exercise affect plasma hormonal and metabolic substrate status among individuals with different phenotypes. To approach this issue, we enrolled subjects with endurance, athletic and obese phenotypes and compared their plasma hormonal and metabolic substrate status.

\section{Materials and methods}

The study included 18, healthy trained and untrained men (mean age $32 \pm 5.4$ years). The participants were divided into three experimental groups with defined body components and level of physical fitness. The inclusion criteria into particular experimental groups were age, body mass, fat content, physical fitness and type of training (Table 1). Exclusion criteria on the other hand included infectious and inflammatory diseases, the use of food supplements or any systemic pharmacological treatment within 2 months prior to the study. All subjects kept their dietary habits constant during the study period. The endurance phenotype - EP group ( $n=6$; mean body mass (BM) $73.8 \pm 7.6 \mathrm{~kg}$; fat content (FAT\%) $11.6 \pm 2.7 \%$; $\mathrm{VO}_{2 \max }$ - $56.8 \pm 4.3 \mathrm{~mL} / \mathrm{min} / \mathrm{kg}$, aerobic endurance trained), the athletic phenotype - AP group $(n=6$; mean body mass (BM) $115 \pm 7.0 \mathrm{~kg}$; fat content (FAT\%) $11.0 \pm 1.7 \%, \mathrm{VO}_{2 \max }$ $43.2 \pm 5.2 \mathrm{~mL} / \mathrm{min} / \mathrm{kg}$, resistance trained), the obesity phenotype - OP group ( $n=6$; mean body mass (BM) $132.5 \pm 3.6 \mathrm{~kg}$; fat content $(\mathrm{FAT} \%) 30.0 \pm 7.7 \%, \mathrm{VO}_{2 \max }-$ $32.8 \pm 4.7 \mathrm{~mL} / \mathrm{min} / \mathrm{kg}$, untrained).

The experiment lasted 10 days. The study consisted of three visits to the laboratory on the 1st, 3rd and 10th day of investigation (Fig. 1).

Visits to the laboratory began at 08:00 h. On the 1st day all participants underwent medical examinations, anthropometric and somatic measurements to exclude any contraindications to the exercise protocol and to classify each subject into one of the three groups. On the 3rd day of experiment, progressive ramp test was performed on a treadmill to determine $\mathrm{VO}_{2 \max }$ and successive loads for the exercise test protocol. Energy intake, as well as macro and micronutrient intakes of all subjects, were determined by the 24-h nutrition recall. Basal metabolic rate (BMR), as well as energy expenditure at rest (REE) and during exercise (EE), were evaluated using the indirect calorimetry method. The participants were informed about the risks and benefits of the study and provided their written consent before the beginning of the experiment. The study received the approval of the Bioethics Committee at the Academy of Physical Education in Katowice, Poland (7/215).

The measurements of body mass were performed on a medical scale with a precision of $0.1 \mathrm{~kg}$. Body composition was evaluated in the morning, between 08:00 and 08:30 h. The day before, the participants had the last meal at 20:00 h. They reported to the laboratory after an overnight fast, refraining from exercise for $48 \mathrm{~h}$. Body composition

This work is licensed under a Creative Commons Attribution-NonCommercial-NoDerivatives 4.0 enternationab ticense.ifica.com at 04/26/2023 12:54:39PM 
Table 1 Basic anthropometric characteristics of the study participants.

\begin{tabular}{l}
\hline Variables \\
\hline Age (years) \\
Height $(\mathrm{cm})$ \\
BMI $\left(\mathrm{kg} / \mathrm{m}^{2}\right)$ \\
$\mathrm{BM}(\mathrm{kg})$ \\
FM $(\%)$ \\
FFM $(\mathrm{kg})$ \\
BMR (kcal) \\
TDEE (kcal) \\
DEI (kcal) \\
Carb $(\%)$ of diet energy \\
Fats $(\%)$ of diet energy \\
Pro $(\%)$ of diet energy
\end{tabular}

\begin{tabular}{c}
\hline Obesity phenotype $(n=6)$ \\
\hline $31 \pm 3.2$ \\
$194.5 \pm 2.12^{\mathrm{a}}$ \\
$34.3 \pm 3.2$ \\
$132.5 \pm 3.6$ \\
$30 \pm 7.7^{\mathrm{a}} \mathrm{C}$ \\
$92.15 \pm 0.7$ \\
$2363 \pm 11.31$ \\
$3054 \pm 169$ \\
$1853.5 \pm 297 \mathrm{kcal}$ \\
$37.5 \pm 10$ \\
$38.5 \pm 0.7$ \\
$25 \pm 9$
\end{tabular}

\begin{tabular}{c}
\hline Athletic phenotype $(n=6)$ \\
\hline $32 \pm 2.8$ \\
$186.3 \pm 4.9$ \\
$33.2 \pm 2.6$ \\
$115 \pm 7.00$ \\
$11 \pm 1.72$ \\
$101.83 \pm 5.8$ \\
$2555.7 \pm 91.7$ \\
$3174 \pm 207$ \\
$3839 \pm 520^{\text {ba }}$ \\
$52 \pm 7$ \\
$21 \pm 8$ \\
$27 \pm 1$
\end{tabular}

\begin{tabular}{c}
\hline Endurance phenotype $(n=6)$ \\
\hline $33 \pm 3.0$ \\
$177.3 \pm 5.03$ \\
$22.9 \pm 2.3$ \\
$73.8 \pm 7.6^{\mathrm{bc}}$ \\
$11.5 \pm 2.17$ \\
$64.9 \pm 5.02^{\mathrm{bc}}$ \\
$1772 \pm 108.2^{\mathrm{bc}}$ \\
$2640 \pm 525$ \\
$2451 \pm 240$ \\
$39 \pm 16$ \\
$30 \pm 10$ \\
$31 \pm 5$
\end{tabular}

Data are expressed as mean \pm S.D., $n=6$.

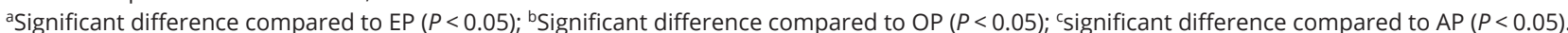
$\mathrm{BM}(\mathrm{kg})$, total body mass; BMI (kg/m²), body mass index; BMR (kcal), basal metabolic rate; DEl, daily energy intake; FFM (kg), fat free mass; FM (\%), fat mass; TDEE (kcal), total daily energy expenditure.

was evaluated using the electrical impedance technique (Inbody 720, Biospace Co., Japan).

The ramp $\mathrm{VO}_{2 \max }$ test was performed on a treadmill (Pulsar; H/P Cosmos, Nussdorf-Traunstein, Germany), starting at a speed of $6 \mathrm{~km} / \mathrm{h}$, which was increased linearly $(1 \mathrm{~km} / \mathrm{h} / 1 \mathrm{~min})$ until volitional exhaustion. During the test, heart rate (HR), oxygen uptake $\left(\mathrm{VO}_{2}\right)$, expired carbon dioxide $\left(\mathrm{CO}_{2}\right)$, minute ventilation (VE), breath frequency (BF) and respiratory exchange ratio (RER) were measured continuously using the MetaLyzer 3B-2R spiroergometer (Cortex, Leipzig, Germany) in the breath-by-breath mode. The following two criteria were used to determine
$\mathrm{VO}_{2 \max }$ : (a) a plateau in $\mathrm{VO}_{2}$ despite an increase in running speed, (b) RER $>1.10$.

Resting energy expenditure was measured immediately after waking at 08:00 h. Measurements were made with the subject in a supine position on a comfortable mattress. RER was measured for $30 \mathrm{~min}$ using the rest test procedure (Metalyzer). The gasses collected during a period of $20 \mathrm{~min}$ were analyzed by the MetaSoft ${ }^{\circledR}$ software.

On the 10th day of the experiment, at 09:00h, after an overnight fast, the participants performed a 35-min progressive treadmill exercise protocol at speeds corresponding to 30,50 and $70 \%$ of their personal

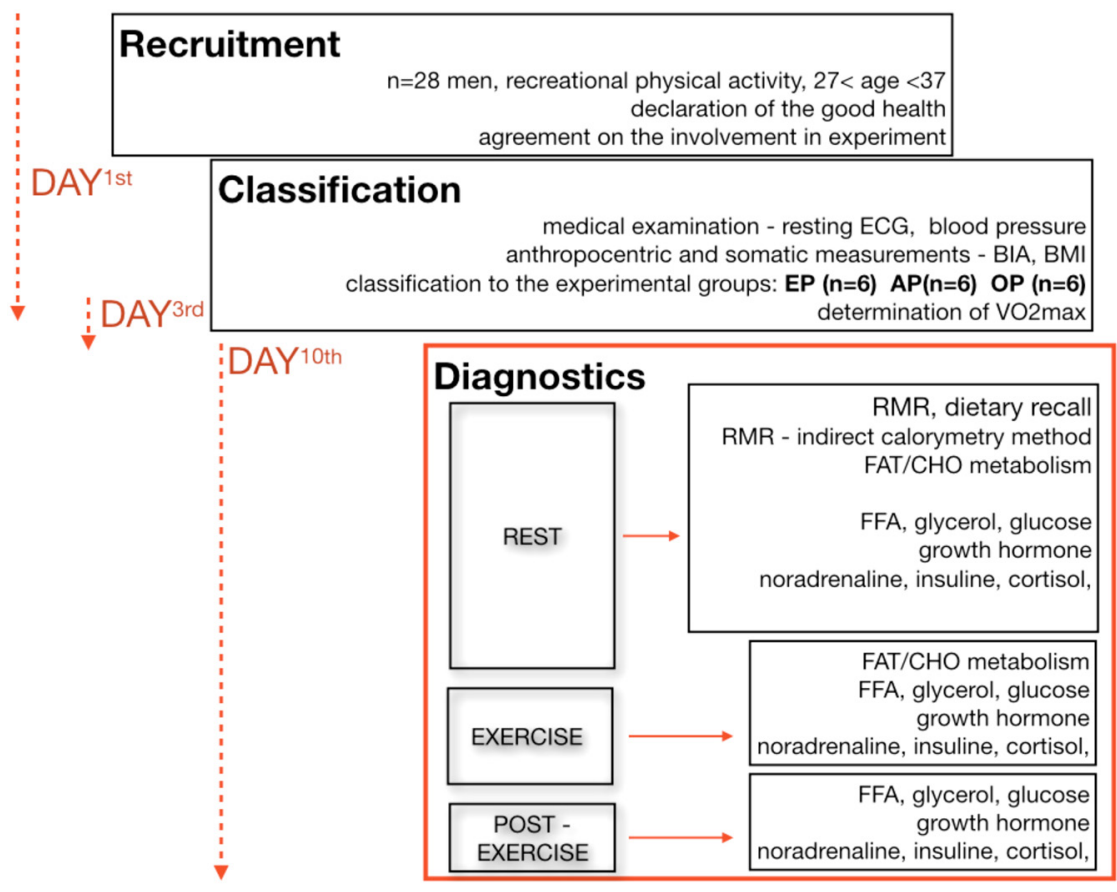

Figure 1

Experimental design flowchart.

https://ec.bioscientifica.com https://doi.org/10.1530/EC-19-0216 (c) 2019 The authors Published by Bioscientifica Ltd
This work is licensed under a Creative Commons Attribution-NonCommercial-NoDerivatives 4.0 enternationab ticense ifica . com at 04/26/2023 12:54:39PM 


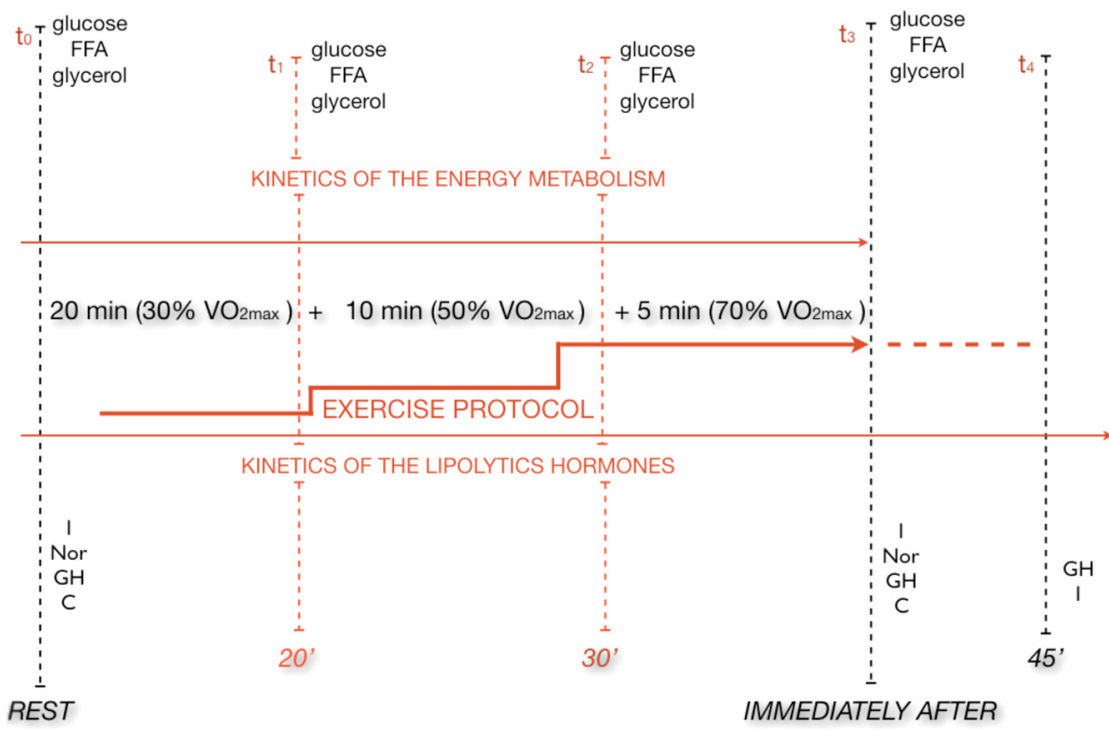

Figure 2

Temporal structure of study protocol.
$\mathrm{VO}_{2 \max }\left(20\right.$-min walk at $30 \% \mathrm{VO}_{2 \max }, 10-\min$ jog at $50 \%$ $\mathrm{VO}_{2 \max }, 5$-min run at $70 \% \mathrm{VO}_{2 \max }$ ) separated by $45 \mathrm{~s}$ of passive rest for blood collection. Blood samples were obtained before ( $\mathrm{t} 0)$, during $\left(20^{\prime}(\mathrm{t} 1), 30^{\prime}(\mathrm{t} 2)\right.$ the exercise protocol, immediately after ( $\mathrm{t} 3$ ), and $45 \mathrm{~min}$ into recovery (t4)) (Fig. 2).

At each of the five time points ( $\mathrm{t} 0, \mathrm{t} 1, \mathrm{t} 2, \mathrm{t} 3, \mathrm{t} 4)$, venous blood samples were collected to determine growth hormone $(\mathrm{GH})$ - $\mathrm{t} 0, \mathrm{t} 3, \mathrm{t} 4$ noradrenaline $(\mathrm{NA})-\mathrm{t} 0, \mathrm{t} 3$, insulin (I) - t0, t3, t4 cortisol (C) - t0, t3, glucose (G) - t0, $\mathrm{t} 1, \mathrm{t} 2, \mathrm{t} 3$, free fatty acids (FFA) $-\mathrm{t} 0, \mathrm{t} 1, \mathrm{t} 2, \mathrm{t} 3$, and glycerol $(\mathrm{GC})-\mathrm{t} 0, \mathrm{t} 1, \mathrm{t} 2, \mathrm{t} 3$. All hormone concentrations as well as FFA and glycerol concentrations were evaluated in blood serum. On the other hand, glucose concentration was evaluated in blood plasma collected for EDTA with NaF. An enzymatic assay kit was used to measure glucose (bioMérieux SA, Marcy l'Etoile, France), and the colorimetric analysis was applied to measure FFA (FA115; Randox, Crumlin, United Kingdom) and glycerol (GY105; Randox). C, GH and I concentrations were measured in duplicate using EDTA plasma and immunoassay kits customized on an automated analyzer (Cobas e411; Roche Diagnostics). NA was measured once by the highperformance liquid chromatography method, what was justified by the recommendations of the producers of the biochemical assays. The intra-assay coefficient of variation was $6.5 \%$ for NA, for cortisol $2.2 \%$, for GH $2.3 \%$ and $4.6 \%$ for insulin.

\section{Statistical analysis}

Shapiro-Wilk, Levene's and Mauchly's tests were used in order to verify the normality, homogeneity and sphericity of the sample's data variances, respectively. All data are presented as mean \pm s.D. Dynamic changes of considered variables were analyzed using time series and fixed base indexes. Verifications of the differences between groups in considered variables were carried out using multivariate ANOVA. Statistical significance was set at $P<0.05$. All statistical analyses were performed using Statistica software and Microsoft Excel.

\section{Results}

All participants completed the described testing protocol. The procedure was carried out in identical environmental conditions with the air temperature of $19.4 \pm 0.4^{\circ} \mathrm{C}$ and humidity of $58 \pm 0.5 \%$ (Carl Roth hydrometer - Germany).

The dynamics of RER, glucose, glycerol and FFA concentrations in particular phenotypes (OP, AP and $\mathrm{EP}$ ) are presented in Table 2A, B, C and D).

Analysis of time series (fixed base indexes) revealed significant changes of RER values (\%), for all time periods from rest to the 35th min of the exercise protocol in all studied groups (Table 2).

Additionally multivariate ANOVA revealed significant differences between groups for RER, glucose, glycerol and FFA (Table 2A, B, C and D).

Analysis of time series (fixed base indexes) revealed significant changes of RER (in the 30th and 35th min for OP, AP and for EP), G (in the 30th min for OP; 20th min for AP and 35th min for EP), GC (in the 30th and 35th min for OP; 35th min for AP and 30th min for EP) and FFA (in the 35th min for OP; 30th and 35th min for AP; in the 30th and 35th min for EP) values expressed in \%, for 
Table 2 Results of time series - fixed base indexes.

\begin{tabular}{|c|c|c|c|c|c|c|}
\hline \multirow[b]{2}{*}{ Time } & \multicolumn{2}{|c|}{ Obesity phenotype } & \multicolumn{2}{|c|}{ Athletic phenotype } & \multicolumn{2}{|c|}{ Endurance phenotype } \\
\hline & Value & $\begin{array}{l}\text { Fixed base } \\
\text { indexes (\%) }\end{array}$ & Value & $\begin{array}{l}\text { Fixed base } \\
\text { indexes (\%) }\end{array}$ & Value & $\begin{array}{l}\text { Fixed base } \\
\text { indexes (\%) }\end{array}$ \\
\hline \multicolumn{7}{|c|}{ A. Respiratory exchange ratio } \\
\hline Rest & 0.76 & Base & 0.92 & Base & 0.75 & Base \\
\hline $20 \mathrm{~min}$ & 0.77 & 4.73 & 0.94 & 1.45 & 0.78 & 3.21 \\
\hline $30 \mathrm{~min}$ & 0.81 & $10.81^{a}$ & 1.02 & $10.14^{\mathrm{b}}$ & 0.87 & $18.35^{\complement}$ \\
\hline $35 \min$ & 0.88 & $18.24^{a}$ & 1.08 & $15.94^{\mathrm{b}}$ & 0.92 & $24.77^{c}$ \\
\hline Time & Value (mmol/L) & $\begin{array}{l}\text { Fixed base } \\
\text { indexes (\%) }\end{array}$ & Value (mmol/L) & $\begin{array}{l}\text { Fixed base } \\
\text { indexes (\%) }\end{array}$ & Value (mmol/L) & $\begin{array}{l}\text { Fixed base } \\
\text { indexes (\%) }\end{array}$ \\
\hline \multicolumn{7}{|l|}{ B. Glucose } \\
\hline Rest & 4.93 & base & 4.21 & base & 4.66 & base \\
\hline $20 \min$ & 4.71 & -4.9 & 3.99 & $-18.7^{b}$ & 4.61 & -6.1 \\
\hline $30 \mathrm{~min}$ & 4.27 & -13.9 & 4.44 & -10.5 & 4.93 & $0.1^{c}$ \\
\hline $35 \mathrm{~min}$ & 4.82 & -1.9 & 4.71 & -4.6 & 5.4 & $10^{c}$ \\
\hline Time & Value $(\mu \mathrm{mol} / \mathrm{L})$ & $\begin{array}{l}\text { Fixed base } \\
\text { indexes (\%) }\end{array}$ & Value ( $\mu \mathrm{mol} / \mathrm{L})$ & $\begin{array}{l}\text { Fixed base } \\
\text { indexes (\%) }\end{array}$ & Value $(\mu \mathrm{mol} / \mathrm{L})$ & $\begin{array}{l}\text { Fixed base } \\
\text { indexes (\%) }\end{array}$ \\
\hline \multicolumn{7}{|l|}{ C. Glycerol } \\
\hline Rest & 61.56 & base & 40.61 & base & 33.40 & base \\
\hline $20 \min$ & 91.55 & 48.7 & 65.23 & 6 & 54.19 & -12 \\
\hline $30 \mathrm{~min}$ & 136.06 & $121^{d}$ & 73.82 & 19.9 & 95.49 & $55.1^{c}$ \\
\hline $35 \mathrm{~min}$ & 163.11 & $164.9^{d}$ & 94.45 & $53.4^{\mathrm{b}}$ & 91.41 & 48.5 \\
\hline Time & Value (mmol/L) & $\begin{array}{l}\text { Fixed base } \\
\text { indexes (\%) }\end{array}$ & Value (mmol/L) & $\begin{array}{l}\text { Fixed base } \\
\text { indexes (\%) }\end{array}$ & Value (mmol/L) & $\begin{array}{l}\text { Fixed base } \\
\text { indexes (\%) }\end{array}$ \\
\hline \multicolumn{7}{|c|}{ D. Free fatty acids } \\
\hline Rest & 0.58 & base & 0.43 & base & 0.32 & base \\
\hline $20 \min$ & 0.51 & -13.2 & 0.56 & 4.3 & 0.44 & 24.1 \\
\hline $30 \mathrm{~min}$ & 0.48 & -18.4 & 0.35 & $-40.4^{b}$ & 0.35 & $-39.1^{c}$ \\
\hline $35 \mathrm{~min}$ & 0.35 & $-40^{d}$ & 0.33 & $-42.9^{b}$ & 0.38 & $-35.5^{c}$ \\
\hline
\end{tabular}

a $P<0.01$ significant difference compared to AP and EP; ${ }^{b} P<0.01$ significant difference compared to OP and $E P ;$ c $P<0.01$ significant difference compared to $O P$ and $A P ;{ }^{d} P<0.01$ significant difference compared to AP.

all time points above the 29th min of exercise (Table 2A, $\mathrm{B}, \mathrm{C}$ and $\mathrm{D})$.

GH values after $35 \mathrm{~min}$ of exercise and $45 \mathrm{~min}$ of recovery were significantly higher in comparison with basal level in all phenotype groups. Similarly, NA values after $35 \mathrm{~min}$ of exercise were significantly higher in comparison with basal level in all examined groups, while I values were significantly lower after $35 \mathrm{~min}$ of exercise (Table 3A and B).

Analysis of time series - fixed base indexes, revealed significant changes of NA (in the 35th min of exercise and 45th min of recovery for OP, AP and EP), GH (in the 35th min of exercise for OP; in the 35th min of exercise and 45 th min of recovery for AP; as well as for the 35 th min

Table 3 Results of time series - fixed base indexes.

\begin{tabular}{|c|c|c|c|c|c|c|}
\hline \multirow[b]{2}{*}{ Time } & \multicolumn{2}{|c|}{ Obesity phenotype } & \multicolumn{2}{|c|}{ Athletic phenotype } & \multicolumn{2}{|c|}{ Endurance phenotype } \\
\hline & Value (ng/mL) & Fixed base indexes (\%) & Value $(\mathrm{ng} / \mathrm{mL})$ & Fixed base indexes (\%) & Value $(\mathrm{ng} / \mathrm{mL})$ & Fixed base indexes (\%) \\
\hline \multicolumn{7}{|l|}{ A. GH } \\
\hline Rest & 0.14 & 100 & 0.49 & 100 & 0.51 & 100 \\
\hline $35^{\prime}$ & 2.51 & $1652.3^{a}$ & 9.03 & $1756.1^{b}$ & 10.87 & $2030.7^{c}$ \\
\hline $45^{\prime}$ res & 0.30 & 108.1 & 5.03 & $934.2^{b}$ & 3.92 & $667.97^{c}$ \\
\hline Time & Value $(\mu \mathrm{IU} / \mathrm{mL})$ & Fixed base indexes (\%) & Value $(\mu \mathrm{IU} / \mathrm{mL})$ & Fixed base indexes (\%) & Value $(\mu \mathrm{IU} / \mathrm{mL})$ & Fixed base indexes (\%) \\
\hline \multicolumn{7}{|l|}{ B. Insulin } \\
\hline Rest & 17.00 & 100 & 3.97 & 100 & 5.02 & 100 \\
\hline $35^{\prime}$ & 8.67 & 50.98 & 1.98 & 50 & 2.95 & 58.80 \\
\hline $45^{\prime}$ res & 13.67 & $80.39^{a}$ & 2.62 & $65.97^{b}$ & 3.78 & $75.42^{c}$ \\
\hline
\end{tabular}

${ }^{a} P<0.01$ significant difference compared to AP and EP; ${ }^{b} P<0.01$ significant difference compared to OP and $E P ;{ }^{c} P<0.01$ significant difference compared to $\mathrm{OP}$ and $\mathrm{AP}$. 
of exercise and 45th min of recovery for $\mathrm{EP}$ ) and I (in the 45 th min of recovery for OP, AP and $\mathrm{EP}$ ) values in \%, for all time points from rest to the 45 th min of recovery.

Multivariate ANOVA showed, statistically significant differences $(P<0.05)$ between all groups for $\mathrm{GH}$, I and NA values at all time points of measurement, while there were no statistically significant differences between groups in cortisol values $(P>0.05)$.

\section{Discussion}

In this study, we identified three phenotypes, i.e. EP, AP, OP using body mass, fat content, physical fitness and type of training as independent variables to investigate selected plasma hormonal and metabolic substrate status in response to continuous exercise of low, moderate and high-intensity in healthy men. These phenotypes can be attributed to different lifestyles and related to non-genetic risk (obesity) or protective (physical activity) factors of non-communicable diseases $(15,16,17,18)$.

The body content of subcutaneous AT is generally attributed to environmental factors (19). This tissue is a key energy storage site in humans which dominates in postprandial conditions (20). One of the primary functions of this tissue is the release of NEFA which are exported to peripheral tissues, mostly skeletal muscles, where they can be used as a substrate for aerobic metabolism. The contribution of NEFA to the total oxidative metabolism is dependent on a variety of factors, among which exercise intensity and duration, as well as dietary and training status play a pivotal role. In this study, regardless of these items, we explored this issue by selecting individuals of different phenotypes who were characterized by different body mass, body fat content and fat distribution, different levels of fat free mass and physical fitness (Table 1).

Fat oxidation during identical relative exercise intensity was repeatedly found to be higher in trained compared with untrained individuals (21). Our analysis has revealed that dynamics of circulating NEFA discloses a biphasic pattern in both athletic and endurance phenotypes, being more pronounced in the second group of individuals. After a 20-min walk at $30 \% \mathrm{VO}_{2 \max }$ the level of NEFA achieved peak values, and next decreased during the run at $50 \% \mathrm{VO}_{2 \max }$ in both phenotypes, when NEFA oxidation reaches a maximal rate (6). These results are in agreement with the view that lipid metabolism is dependent on the intensity of exercise, and in line with such an assumption is also a further lack of a drop in FFA level despite the increase in exercise intensity $\left(70 \% \mathrm{VO}_{2 \max }\right)$.
It was shown that plasma NEFA uptake and oxidation was limited during high-intensity exercise (22). Under these circumstances intramuscular TG hydrolysis may at least partially substitute reduced accessibility of NEFA from plasma by adrenaline (23) and contraction (24) stimulation of hormone-sensitive lipase (HSL) within muscle cells.

It seems that the efficiency of fat oxidation at muscle cell level is the most likely controlling factor, which can be modified by substrate availability before the appearance of leveling off (about $85 \%$ of $\mathrm{VO}_{2 \max }$ ) in net NEFA (predominantly long chain) uptake. This was confirmed in our study by a constant rise of plasma glycerol levels and non-parallel changes in plasma NEFA during particular exercise intensities in AP and EP individuals. A linear drop in plasma NEFA in the obese phenotype suggests that this mechanism likely operates in a different manner in this group of subjects, and may be attributed to their dietary status, which was characterized by a significantly higher energy intake from fats (Table 1). The driving force of the FFA flux from vascular space to muscle cells is assumed to be the concentration gradient between these compartments, which could be kept upregulated (higher plasma NEFA level) in obese phenotype individuals within all ranges of exercise intensities. The view that delivery from vascular space can play an important role in fat metabolism of the above mentioned subjects also appeared from RER values which were lower both at 30 and $50 \% \mathrm{VO}_{2 \max }$ in these subjects in comparison to other investigated groups, indicating their higher reliance on lipids as a source of energy supply. On the other hand, the observed changes in RER in the athletic phenotype indicate the highest glucose contribution to oxidative metabolism. Since the dynamics of insulin concentration had a similar pattern in all phenotypes, the differences in glucose concentration between phenotypes may reflect the activation of different regulatory mechanisms at the muscle cellular level including NEFA re-esterification. Among regulatory factors that may play a major role in this phenomenon, one can point to differences in muscle insulin sensitivity, different activation of contraction-induced insulin signaling pathways and impact of substrate and exercise on muscle malonylCoA concentration. Physiological catecholamines, GH and insulin are primary controllers of both AT lipolysis and glucose metabolism. Catecholamines and GH have a stimulatory effect on AT metabolism, while insulin inhibits lipolysis. There is significant evidence for a hormone-coordinated regulation of AT TG hydrolysis during prolonged exercise (25). A linear increase in plasma NA and GH and a drop in plasma I observed in our study

This work is licensed under a Creative Commons Attribution-NonCommercial-NoDerivatives 4.0 Internationab ticense.ifica.com at 04/26/2023 12:54:39PM 
indicate that the above mentioned hormone regulatory mechanisms expressed this general physiological pattern in all investigated phenotypes, and this mechanism seems not to be affected by phenotype.

Exercise is a major stimulus of GH secretion. GH becomes an important regulator of lipolysis during prolonged fasting, where lipolysis is stimulated together with increased GH and decreased insulin levels $(21,26)$. Previous studies showed that circulating GH concentration can be regulated by several factors including food intake (27). It could thus be argued that a slower decrease in GH plasma concentration seen in individuals with athletic phenotype over the recovery period could be attributed to their nutritional status and content of amino acids in diet.

It has been established that adipocytes contribute to a lesser extent to whole-body insulin stimulated glucose disposal in normal individuals compared with skeletal muscle. Consequently, the primary and most evident site of insulin action should be observed in individuals with a higher FFM. This variable reached the highest values both in athletic and surprisingly obesity phenotypes. However, the later phenotype is also characterized by the highest content of FM. Because of similar exercise induced drops in insulin levels in all groups, changes in body composition could be considered as another factor taking part in different exercise induced adaptations between athletic and obesity phenotypes. These results suggest that individuals with obesity phenotype are more susceptible to insulin resistance, what has been confirmed in obese individuals (28).

Among known catecholamines, A belongs to the best investigated in term of its lipolytic effect. However, NA was detected in the interstitial fluid of adipose tissue at concentrations similar to those observed in plasma (29). This suggests that NA impacts AT lipolysis, similarly to A, and can be expressed via a dual mechanism: direct action on adrenergic receptors located in adipose cell membranes (30), and indirectly, by regulation of blood flow to AT (31). Many studies are not fully conclusive, as some authors found enhanced whole-body lipolysis during exercise in trained compared with untrained subjects $(21,32)$, while others did not find these differences (33). Such an association may be expected in face of results revealing that variation in catecholamine pathway genes contribute to the inter-individual variability in plasma NA and $\mathrm{A}$ concentrations, both at rest and after recovery from exercise (33).

In summary, the present study provides more data about the metabolic and hormonal responses to low and moderate intensity aerobic exercise. Our findings highlight the benefits of targeted training protocols dependent on phenotype and dietary habits. The results of this research can contribute to the individualization of training protocols, which will optimize the lipolytic effect. Combining phenotype and metabolism with a range of counter-regulatory lipolytic hormones provides a more complete perspective on cross-talk between the endocrine system and exercise metabolism. It has been shown experimentally that inhibition of whole-body lipolysis improves whole-body insulin sensitivity and metabolic profile of subjects. Studies investigating the combined effect of lipolysis inhibition and different types of physical activity may bring new information into this field of study. The results indicate that the rate of lipolysis, hormonal and metabolic response to aerobic exercise to some extent depends on the individuals' phenotype. Thus, exercise type, duration and intensity have to be strictly individualized in relation to phenotype in order to reach optimal metabolic benefits. The observed changes in RMR and RER indicate the highest glucose contribution to oxidative metabolism in the athletic phenotype, suggesting the importance of FFM in the regulation of lipolysis and energy expenditure. For people with a high content of lean body mass and significant glycogen stores, performing high-intensity exercise $\left(>70 \% \mathrm{VO}_{2 \max }\right.$ ) seems to be a rational training strategy for improving lipolysis. Moreover, in overweight and obese people, two mechanisms regulating exercise metabolism and especially lipolysis are significantly blunted. First of all post-exercise insulin decrease is significantly lower and the efflux of GH and noradrenaline is much smaller than in resistance and endurance trained subjects. Thus, for people with obesity using lower intensity aerobic efforts $\left(50 \% \mathrm{VO}_{2 \max }\right)$ seems most appropriate for improving fat metabolism and inducing favorable changes in body composition.

\section{Declaration of interest}

The authors declare that there is no conflict of interest that could be perceived as prejudicing the impartiality of the research reported.

\section{Funding}

This work was supported by the Ministry of Science and Higher Education of Poland under Grant NRSA3 03953 and NRSA4 04054.

\section{Acknowledgements}

The study was designed by Jakub Chycki and Adam Zajac; data were collected and analyzed by Jakub Chycki, Adam Maszczyk and Józef Langfort; data interpretation and manuscript preparation were undertaken by Jakub Chycki, Małgorzata Michalczyk, Adam Zajac and Józef Langfort. All authors approved the final version of the manuscript. 


\section{References}

1 Brockmann GA, Tsaih SW, Neuschl C, Churchill GA \& Li R. Genetic factors contributing to obesity and body weight can act through mechanisms affecting muscle weight, fat weight, or both Physiological Genomics 200936 114-126. (https://doi.org/10.1152/ physiolgenomics.90277.2008)

2 Jaksic D \& Cvetkovic M. Neuronal network analysis of somatotype differences among males related to the manifestation of motor abilities. Acta Kinesiologia 20093 107-113.

3 Sethi JK \& Vidal-Puig AJ. Thematic review series: adipocyte biology. Adipose tissue function and plasticity orchestrate nutritional adaptations. Journal of Lipid Research 200748 1253-1262. (https:// doi.org/10.1194/jlr.R700005-JLR200)

4 Harrington TA, Thomas EL, Frost G, Modi N \& Bell JD. Distribution of adipose tissue in the newborn. Pediatric Research 200455 437-441. (https://doi.org/10.1203/01.PDR.0000111202.29433.2D)

5 Handy O, Porramatikul S \& Al-Ozairi E. Metabolic obesity: the paradox between visceral and subcutaneous fat. Current Diabetes Reviews 20062 367-373. (https://doi.org/10.2174/1573399810602040367)

6 Romijn JA, Coyle EF, Sidossis LS, Rosenblatt J \& Wolfe RR. Substrate metabolism during different exercise intensities in endurance-trained women. Journal of Applied Physiology 200088 1707-1714. (https:// doi.org/10.1152/jappl.2000.88.5.1707)

7 Klein S, Coyle EF \& Wolfe RR. Fat metabolism during low-intensity exercise in endurance-trained and untrained men. American Journal of Physiology 1994267 E934-E940. (https://doi.org/10.1152/ ajpendo.1994.267.6.E934)

8 Horowitz JF, Mora-Rodriguez R, Byerley LO \& Coyle EF. Substrate metabolism when subjects are fed carbohydrate during exercise. American Journal of Physiology 1999276 E828-E835. (https://doi. org/10.1152/ajpendo.1999.276.5.E828)

9 Achten J \& Jeukendrup AE. Optimizing fat oxidation through exercise and diet. Nutrition 200420 716-727. (https://doi. org/10.1016/j.nut.2004.04.005)

10 McMurray RG \& Hackney AC. Interactions of metabolic hormones, adipose tissue and exercise. Sports Medicine 200535 393-412. (https://doi.org/10.2165/00007256-200535050-00003)

11 Bajer B, Vlcek M, Galusova A, Imrich R \& Penesova A. Exercise associated hormonal signals as powerful determinants of an effective fat mass loss. Endocrine Regulations 201549 151-163. (https://doi. org/10.4149/endo_2015_03_151)

12 Schutz Y. Concept of fat balance in human obesity revisited with particular reference to de novo lipogenesis. International Journal of Obesity and Related Metabolic Disorders 200428 (Supplement 4) S3-S11. (https://doi.org/10.1038/sj.ijo.0802852)

13 Henderson GC, Fattor JA, Horning MA, Faghihnia N, Johnson ML, Mau TL, Luke-Zeitoun M \& Brooks GA. Lipolysis and fatty acid metabolism in men and women during the postexercise recovery period. Journal of Physiology 2007584 963-981. (https://doi. org/10.1113/jphysiol.2007.137331)

14 Goodpaster BH \& Sparks LM. Metabolic flexibility in health and diseases. Cell Metabolism 201725 1027-1036. (https://doi. org/10.1016/j.cmet.2017.04.015)

15 McLaren L. Socioeconomic status and obesity. Epidemiologic Reviews 200729 29-48. (https://doi.org/10.1093/epirev/mxm001)

16 O'Keefe EL, DiNicolantonio JJ, Patil H, Helzberg JH \& Lavie CJ. Lifestyle choices fuel epidemic of diabetes and cardiovascular disease among Asian Indians. Progress in Cardiovascular Diseases 201658 505-513. (https://doi.org/10.1016/j.pcad.2015.08.010)

17 Archer E, Lavie CJ \& Hill JO. The contributions of diet, genes an physical activity to the etiology of obesity: contrary evidence and consilience. Progress in Cardiovascular Diseases 201861 89-102. (https://doi.org/10.1016/j.pcad.2018.06.002)

18 Ortega FB, Cadenas-Sanchez C, Migueles JH, Labyen I, Ruiz JR, Sui X, Blair SN, Martinez-Vizcaino V \& Lavie CJ. Role of physical activity and fitness in the characterization and prognosis of the metabolically healthy obesity phenotype: a systematic review and meta-analysis. Progress in Cardiovascular Diseases 201861 190-205. (https://doi. org/10.1016/j.pcad.2018.07.008)

19 Weaver JU. Classical endocrine diseases causing obesity. Frontiers of Hormone Research 200836 212-228. (https://doi. org/10.1159/000115367)

20 Horowitz JF. Fatty acid mobilization from adipose tissue during exercise. Trends in Endocrinology and Metabolism 200314 386-392. (https://doi.org/10.1016/S1043-2760(03)00143-7)

21 Trapp EG, Chisholm DJ \& Boutcher SH. Metabolic response of trained and untrained women during high-intensity intermittent cycle exercise. American Journal of Physiology: Regulatory, Integrative and Comparative Physiology 2007293 R2370-R2375. (https://doi. org/10.1152/ajpregu.00780.2006)

22 Sidossis LS, Gastaldelli S, Klein S \& Wolfe RR. Regulation of plasma FFA oxidation during low and high intensity exercise. American Journal of Physiology 1997272 1065-1070.

23 Langfort J, Ploug T, Iglemann J, Saldo M, Holm C \& Galbo H. Expression of hormone-sensitive lipase and its regulation by adrenaline in skeletal muscle. Biochemical Journal 1999340 459-465.

24 Langfort J, Ploug T, Ihlemann J, Holm C \& Galbo H. Stimulation of hormone-sensitive lipase activity by contractions in rat skeletal muscle. Biochemical Journal 2000351 207-214. (https://doi. org/10.1042/0264-6021:3510207)

25 Jensen MD. Fate of fatty acids at rest and during exercise: regulatory mechanisms. Acta Physiologica Scandinavica 2003178 385-390. (https://doi.org/10.1046/j.1365-201X.2003.01167.x)

26 Zając A, Wilk M, Socha T, Maszczyk A \& Chycki J. Effects of growth hormone and testosterone therapy on aerobic and anaerobic fitness, body composition and lipoprotein profile in middle-aged men. Annals of Agricultural and Environmental Medicine 201421 156-160.

27 Giustina A \& Veldhuis JD. Pathophysiology of the neuroregulation of growth hormone secretion in experimental animals and the human. Endocrine Reviews 199819 717-797. (https://doi.org/10.1210/ edrv.19.6.0353)

28 Schwartsburg PM. Catabolic and anabolic faces of insulin resistance and their disorders: a new insight into circadian control of metabolic disorders leading to diabetes. Future Science OA 20173 FSO201. (https://doi.org/10.4155/fsoa-2017-0015)

29 Gronlund B, Astrup A, Bie P \& Christensen NJ. Noradrenaline realease in skeletal muscle and in adipose tissue studied by microdialysis. Clinical Science 199180 595-598. (https://doi.org/10.1042/cs0800595)

30 Armer P. Control of lipolysis and its relevance to development of obesity in man. Diabetes/Metabolism Reviews 19884 507-515. (https://doi.org/10.1002/dmr.5610040507)

31 Alemany M. Regulation of adipose tissue energy availability through blood flow control in the metabolic syndrome. Free Radical Biology and Medicine 201252 2108-2119. (https://doi.org/10.1016/j. freeradbiomed.2012.03.003)

32 Stallknecht B, Simonsen L, Bulow J, Vinten J \& Galbo H. Effect of training on epinephrine-stimulated lipolysis determined by microdialysis in human adipose tissue. American Journal of Physiology 1995269 E1059-E1066. (https://doi.org/10.1152/ajpendo.1995.269.6.E1059)

33 Klein S, Weber JM, Coyle EF \& Wolfe RR. Effect of endurance training on glycerol kinetics during strenuous exercise in humans. Metabolism: Clinical and Experimental 199645 357-361. (https://doi. org/10.1016/S0026-0495(96)90291-7)

Received in final form 1 May 2019

Accepted 28 May 2019

Accepted Preprint published online 28 May 2019

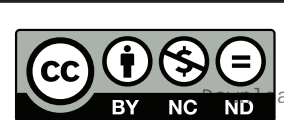

This work is licensed under a Creative Commons Attribution-NonCommercial-NoDerivatives 4.0 Internationab bicense.ifica . com at 04/26/2023 12:54:39PM 